\title{
Nutritional ecology bridges the gap between mites' biological and ecological research results under Mediterranean environment
}

\author{
Mohamed M. Abou-Setta \\ Plant Protection Research Institute, A.R.C., Dokki, Giza 12618, Egypt. E-mail, abousetta_mm@yahoo.com
}

\begin{abstract}
Under Mediterranean conditions a conflict between mite laboratory studies concerning thermal effects on growth durations, rates, life table parameters and field population dynamics was observed. Laboratory studies aim at determining growth rates at different temperatures are conducted to elucidate field ecological patterns. Laboratory growth rate results can be presented mathematically within a certain range as linear relationship. It is the base of Degree-Day models used for prediction models. Under field conditions maximum and minimum temperatures and mean RH are considered as the influential weather factors. Under Mediterranean moderate climate and artificial irrigation systems, annual crops are produced throughout the year and some crops and perennials grow year around. The change in mite pest populations shows non-linear relationships during each plant growth seasons regardless of the change in environmental factors. This contradicts lab results at constant temperatures. Considering nutritional ecology bridges this gap. The change in available nutritional value (which is variable during the growing season) becomes the main factor. This factor is affected by host plant biological phenomena (different stages of growth and their nutritional contents). This factor is a dynamic one and can be included mathematically as plant age of the third degree (i.e. $\mathrm{X}, \mathrm{X}^{2}$ and $\mathrm{X}^{3}$, respectively) in a polynomial equation along with other environmental factors. The regression model becomes $\left(Y=a \pm b_{1} T \operatorname{Tmax} \pm b_{2} T \operatorname{Tmin} \pm b_{3} R H \pm b_{4} X \pm b_{5} X^{2} \pm b_{6} X^{3}\right)$. Published results reveal that this factor is more influential on mite population dynamics than environmental ones.
\end{abstract}

Keywords: Laboratory studies, population dynamics, life tables, degree-days, polynomial, plant age.

\section{INTRODUCTION}

Integrated Pest Management and field crop practices rely on the use of all available control methods to keep the relationship between plant hosts and their pests in harmony to achieve maximum yield and minimal environmental disturbance. Understanding the behavior of both host plants and their pests is the first step in IPM programs. Laboratory and field studies are conducted to elucidate the effect of biotic and abiotic factors on acarine pest populations' dynamics. The aim of this article is to review different statistical procedures which are appropriate for handling laboratory biological studies and ecological ones concerning different studied factors and fill the gap between their results when occur.

\section{Biological basic studies common practices background:}

To assess the effect of separate factors on the behavior of an organism, studies are usually conducted under controlled laboratory conditions. Analysis of variance (ANOVA) with different levels of complications can be used to determine the effect of the tested factors (i.e. one, two ways and factorial), followed by means separation to obtain the significance between the various factors (for example Tukey's HSD, LSD and Duncan multi-range test).

To assess the effect of different levels of a single factor, correlation and regression is used. Simple correlation and regression is applied to linear relationships. If the response is no-linear, then we use non-linear (polynomial) models. A common mistake is to use analysis of variance to distinguish between different levels of a single factor.

The combined effect of multiple factors with different levels, multiple regressions can be used and it can include linear and non-linear models in the same application.

For the effect of discrete and continuous factors together on the same experiment results, we use two-way analysis or factor analysis (ignoring the influence of continuous ones).

Thermal effect as single factor:

Biological studies are usually performed under controlled laboratory conditions where the plants and associated mites do not have selftemperature control systems (poikilotherm animals).

The speed of chemical reactions and thus the speed of growth of an organism depend on the temperature in the presence of appropriate food source. As a result, the growth of both the host and 
the pests associated with it depends on the surrounding environmental factors, especially temperature.

The relationship between the growth period of an individual and temperature (within a range that allows him to survive) can be expressed globally as the second degree of non-linear polynomial relationship (i.e. $Y=a \pm b_{1} X \pm b_{2} X^{2}$ ), where $a=$ constant and $b_{1}$ and $b_{2}$ are used for temperature slopes in the first and second parts of the response curve, $\mathrm{X}$ is the tested temperature in degrees Celsius and $X_{2}$ is the tested temperature raised to the power of 2 .

This relationship can be expressed mathematically as a growth rate (1/time) in a linear one (i.e. $Y=a \pm b X$ ). These statistical patterns can be easily applied using available software applications such as Excel ${ }^{\circledR}$.

It is important to note that the constant (a) for developmental rates has to be negative. Otherwise, it would indicate that growth could occur at $0{ }^{\circ} \mathrm{C}$ or below.

This linear relationship leads to the calculation of a growth threshold of zero growth $\left(t_{0}\right)$. The inverse of the regression coefficient $(1 / b)$ also reveals the value $(K)$ required for each stage in temperature degree day units (DDUs) as a physiological time in excess of $\left(\mathrm{t}_{\mathrm{o}}\right)$. Physiological time combines the effect of specific temperature and time (within the growth range).

This leads to the following patterns:

$\mathrm{t}_{\mathrm{o}}\left({ }^{\circ} \mathrm{C}\right)=-\mathrm{a} / \mathrm{b}$ and $\mathrm{K}=1 / \mathrm{b}$ (DDUs) also $\mathrm{K}=\mathrm{T} *\left(\mathrm{t}-\mathrm{t}_{\mathrm{o}}\right)$

Where: $t_{0}=$ zero growth ${ }^{\circ} \mathrm{C}, \mathrm{b}=$ slope of growth rate line, $\mathrm{K}=$ temperature days, $\mathrm{T}=$ growth time, and $\mathrm{t}=$ prevailing temperature .

The effect of the full range of temperatures can be expressed by a more complex non-linear function. Models are available for a full range of temperatures (Kim et al. 2009).

\section{Life table parameters (bioavailability):}

Two types of life tables are worth noting here. The first is for laboratory studies (age structure) and the second is for field studies (time structure). The former model is conducted under standard laboratory conditions, while the later is conducted under current environmental conditions, especially in relatively stable environments such as forests. Both of them are concerned with birth and death rates. This article is concerned with the first type (age structure) only.

Reporting biological studied usually does not include mortality rates at different stages. This parameter is included in life table parameters, which affects population growth rates. The results obtained include full-stage survival rate, sex ratio (females/total), net reproduction rate (Ro), mean generation time $(\mathrm{T})$, inherited rate of increase $\left(\mathrm{r}_{\mathrm{m}}\right)$ and finite increase rate $\left(\lambda\right.$ or $\left.\exp r_{m}\right)$. Under these laboratory conditions, the only factor is considered while other factors are constant (i.e. temperature or nutritional value of the host plant or prey).

These parameters based on Birch (1948), whom adopted the Lotka (1925) model of human overpopulation rates to the model of human societies. This model assumes that the population increases at a rate of $\mathrm{dN} / \mathrm{dt}=\mathrm{rN}$. The value of $\mathrm{r}$ can be calculated from the equation. The inherited rate of increase is best defined as the constant ' $r$ ' in the differential equation for population increase in infinite environment conditions. The value of $\mathrm{r}$ can be calculated from the equation $\Sigma \mathrm{e}^{-\mathrm{rx}} 1_{\mathrm{x}} \mathrm{m}_{\mathrm{x}} \mathrm{d}_{\mathrm{x}}=1$. The main parameters of life schedule are heritable rate of increase $\left(r_{m}\right)$, limited growth rate $\left(\exp r_{m}\right)$, mean generation time $(\mathrm{T})$ and net reproduction rate (Ro).

A computer program was developed in the BASIC computer language to calculate the life table parameters using experimental biological data (Abou-Setta et al. 1986) according to the method of Birch (1948). It has been used in quite few published papers.

\section{Adjusting RH:}

Adjusting percent relative humidity (\% RH) during biological mite studies is possible using over saturated solutions of different soluble salts (Winston and Bates 1960). A common examples are using $\mathrm{NaCl}$ over saturated solutions can keep $\mathrm{RH}$ within rearing boxes at $75 \%$ while using $\mathrm{KCl}$ keeps it at $85 \%$.

\section{Statistical analysis of environmental studies of mites with intergenerational overlap:}

Under Mediterranean environmental conditions (i.e. Egypt), the average daily maximum temperature ranges between 20 and $45^{\circ} \mathrm{C}$ throughout the year. The minimum temperature ranges between 5 and $22^{\circ} \mathrm{C}$ depending on latitude 
(20 to 32 degrees North). Minimum temperatures occur around mid-Feb. and maximum temperatures around mid-Aug. Under this moderate temperates climate, depending on artificial irrigation and water availability, crops are produced throughout the year in three common growing seasons for annual crops (summer, niley and winter seasons).

Crops with relatively high thermal requirements (such as cotton, corn, rice, etc.) are grown in the summer season, starting in early spring and continuing until late summer. Some of these crops are planted in late summer and up to mid-autumn as a niley season. Crops require relatively lower thermal conditions (such as wheat, barley, lentils, alfalfa, etc.) are planted in the fall and continue until the following spring as a winter season. Also, under this moderate climate, some vegetable crops (such as tomatoes are grown throughout the year), while other crops (such as sugar cane) grow throughout the year with higher growth rates during the summer.

Regardless of planting date, all crops are subject to arthropod pest infestation (including mites), which peaks at some time during the crop growing season.

Researchers usually try to relate field and laboratory results. Simple correlation, regression, and partial regression are used to illustrate these relationships. They use maximum and minimum temperatures, relative humidity, or other independent factors and pest abundance as dependent. They expect a high response agreement between dependent and independent factors as they appear under laboratory conditions.

Statistical analysis in this way sometimes reveals a decrease in the harmony rate or inverse relationships. This occurs due to neglecting of the host's vegetative phenomena (i.e. the nutritional value available to the pest from the host over the course of the growing season) and it is a variable one.

The aim of this article is to overcome this conflict by including the nutritional value over the host plant as dynamic factor over the growing season regardless prevailing weather factors.

MATERIAL AND METHODS

Examples of different published research results for mite studies was picked up and retreated in a way and prober comments are suggested.

\section{RESULTS AND DISCUSSION}

The following is an example of applying a linear model to different growth durations of predatory mite with applying linear model and life table parameters under consecutive temperatures (Tables 1 and 2).

\section{Important note:}

It is noticed from this example that the temperature increase was reflected in the decrease in the growth period for all phases and therefore, the increase in the growth rate to $30^{\circ} \mathrm{C}$, and that this effect took a reveres at $32^{\circ} \mathrm{C}$. At the same time, the highest expected heritable ability to reproduce was at $25^{\circ} \mathrm{C}$, which corresponds to the highest value of the females' ability to replicate themselves in one generation (Ro). Therefore, the degree of $30^{\circ} \mathrm{C}$ gave the highest growth rates, while $25^{\circ} \mathrm{C}$ can be considered as the optimum for the growth and reproduction of this organism Figure (1).

Different factors influence the estimated heritable rate of increase in the insect or spider species. The main factor is the length of generation time. The relationship between generations and the duration of oviposition varies with the species. In the event that oviposition period is longer than the generation time, the calculation of measures of life tables can be performed using the data of 1 oviposition period similar to the length of the generation time to reach an increase rate very close to the expected maximum rate of intrinsic increase for these species (Abou-Setta and Childers 1991).

\section{Effect of different hosts on the biology of the mites:}

Life table parameters can be used to distinguish between the preference for different hosts or appropriate factors affecting the biology of the organism (Table 3). Host suitability is characterized by faster growth, lower heat requirements, or higher reproduction rate. It is noticeable from this example that the different feeding type of Typhlodromalus peregrinus on Tetranychus urticae (Koch) or Panonychus citri (McGregor) as well as Malephora crocra, Quercus virginiana and Tyhpa latifolia pollens. 
Table 1. Applying linear model to different growth rates of Galendromus helveolus Chant (Acari: Phytoseiidae) females at different temperatures (after Caceres and Childers 1991).

\begin{tabular}{ccccccc}
\hline Temperature ${ }^{\circ} \mathrm{C}$ & & Egg & Larva & Protonymph & Deutonymph & Total \\
\hline & 16 & 4.08 & 1.33 & 4.10 & 4.00 & 13.51 \\
\cline { 2 - 7 } & 18 & 3.92 & 1.38 & 3.78 & 3.55 & 12.63 \\
\cline { 2 - 7 } Duration (days) & 20 & 3.30 & 1.26 & 2.66 & 2.60 & 9.82 \\
\cline { 2 - 7 } & 25 & 2.00 & 0.79 & 1.60 & 1.32 & 5.71 \\
\cline { 2 - 7 } & 30 & 1.68 & 0.64 & 1.05 & 1.22 & 4.59 \\
\hline & 32 & 1.74 & 0.66 & 1.45 & 1.01 & 4.86 \\
\hline \multirow{5}{*}{ Developmental rate } & 16 & 0.245 & 0.752 & 0.244 & 0.250 & 0.074 \\
\cline { 2 - 7 } & 18 & 0.255 & 0.725 & 0.265 & 0.282 & 0.079 \\
\cline { 2 - 7 } & 20 & 0.303 & 0.794 & 0.376 & 0.385 & 0.102 \\
\cline { 2 - 7 } & 25 & 0.500 & 1.266 & 0.625 & 0.758 & 0.175 \\
\hline & 30 & 0.595 & 1.563 & 0.952 & 0.820 & 0.218 \\
\hline \multirow{5yyyyyy}{*}{ Regression values } & 32 & 0.575 & 1.515 & 0.690 & 0.990 & 0.206 \\
\cline { 2 - 7 } & $\mathrm{r}$ & 0.975 & 0.973 & 0.917 & 0.981 & 0.976 \\
\cline { 2 - 7 } & $\mathrm{a}$ & -0.155 & -0.264 & -0.390 & -0.522 & -0.085 \\
\cline { 2 - 7 } & $\mathrm{b}$ & 0.024 & 0.058 & 0.039 & 0.047 & 0.010 \\
\cline { 2 - 7 } & $\mathrm{K}$ & 6.425 & 4.544 & 10.009 & 11.124 & 8.763 \\
\hline
\end{tabular}

Table 2. Life table parameters under consecutive temperatures of Galendromus helveolus Chant (after Caceres and Childers 1991).

\begin{tabular}{lccccc}
\hline Parameter & $16^{\circ} \mathrm{C}$ & $20^{\circ} \mathrm{C}$ & $25^{\circ} \mathrm{C}$ & $30^{\circ} \mathrm{C}$ & $32^{\circ} \mathrm{C}$ \\
\hline Sex ratio (females/total) & 0.79 & 0.63 & 0.83 & 0.74 & 0.80 \\
\hline Developmental time (days) & 13.46 & 9.66 & 5.7 & 4.61 & 4.84 \\
\hline Pre-oviposition period (days) & 2.89 & 2.83 & 1.55 & 1.53 & 2.00 \\
\hline Mean total fecundity (eggs/female) & 12.20 & 28.92 & 39.31 & 34.08 & 18.48 \\
\hline Net reproductive rate (Ro) & 6.28 & 16.22 & 28.06 & 18.91 & 4.58 \\
\hline Mean generation time in days $(\mathrm{T})$ & 20.79 & 20.66 & 12.91 & 10.23 & 11.9 \\
\hline Intrinsic rate of increase $\left(\mathrm{r}_{\mathrm{m}}\right)$ & 0.088 & 0.135 & 0.258 & 0.287 & 0.124 \\
\hline Finite rate of increase $\left(\exp \mathrm{r}_{\mathrm{m}}\right)$ & 1.09 & 1.14 & 1.29 & 1.33 & 1.13 \\
\hline
\end{tabular}

Table 3. Using life table parameters to different foods at the same temperature of Typhlodromalus peregrinus (Acari: Phytoseiidae) female (after Fouly et al. 1995).

\begin{tabular}{lccccccc}
\hline \multicolumn{1}{c}{ Food source } & $\begin{array}{c}\% \\
\text { females }\end{array}$ & $\begin{array}{c}\text { Generation } \\
\text { (days) }\end{array}$ & Fecundity & $\mathrm{R}_{\mathrm{o}}$ & $\begin{array}{c}\mathrm{T} \\
\text { (days) }\end{array}$ & $\mathrm{r}_{\mathrm{m}}$ & $\exp \left(\mathrm{r}_{\mathrm{m}}\right)$ \\
\hline Tetranychus urticae & 53 & 8.12 & 53.7 & 25.32 & 14.43 & 0.224 & 1.25 \\
\hline Panonychus citri & 56 & 8.76 & 47.11 & 24 & 15.15 & 0.210 & 1.23 \\
\hline Malephora crocra & 63 & 8.91 & 49.48 & 26.65 & 14.79 & 0.219 & 1.24 \\
\hline Quercus virginiana & 55 & 8.78 & 30.38 & 14.2 & 13.75 & 0.193 & 1.21 \\
\hline Typha latifolia & 54 & 9.42 & 24.25 & 14.04 & 14.63 & 0.170 & 1.18 \\
\hline T. urticae + M. crocra & 56 & 8.13 & 36.37 & 17.89 & 13.57 & 0.212 & 1.24 \\
\hline T. urticae + Q. virginiana & 54 & 9.00 & 33.07 & 15.18 & 14.31 & 0.190 & 1.21 \\
\hline T. urticae + T. latifolia & 57 & 8.63 & 31.63 & 15.32 & 14.21 & 0.192 & 1.21 \\
\hline
\end{tabular}




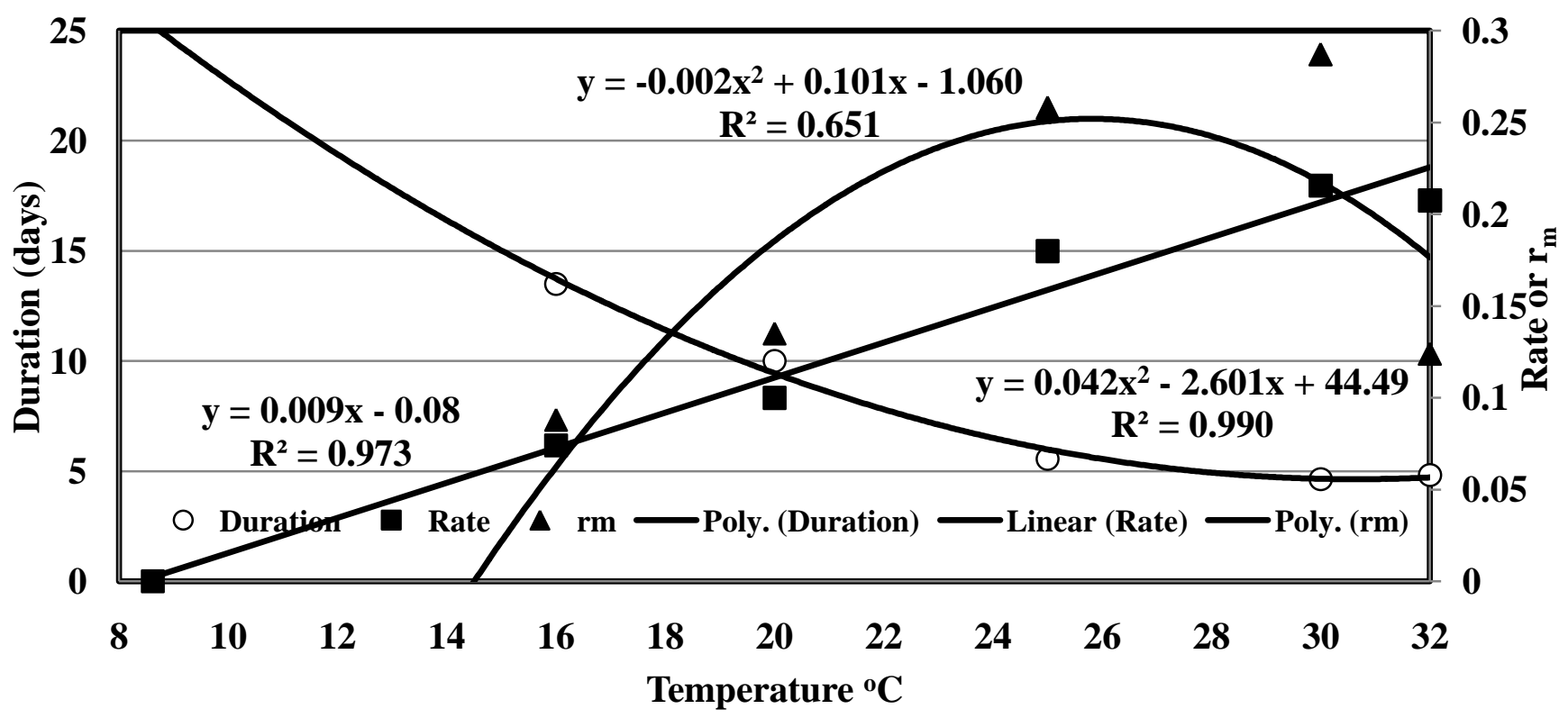

Figure 1. Linear relationship of growth rates, non-linear for growth durations and the inherited reproduction rate of Galendromus helveolus Chant females under laboratory conditions (prepared after Caceres and Childers 1991).

Also, feeding on a mixture of these three pollen grains and $T$. urticae did not increase these measures. It is noticeable that the life table parameters were highest when fed on $T$. urticae, $P$. citri or $M$. crocra pollen. It was much lower on pollen of $Q$. virginiana and $T$. latifolia. Also, feeding on a mixture of these two pollen grains with T. urticae did not increase these measurements (Table 3).

\section{Determination of the minimum and maximum} temperature for growth:

1. Application of degree day models to field prediction models requires the determination of a minimum of theoretical zero growth temperature $\left(t_{0}\right)$ and an empirical maximum of optimal growth rates.

2. The application of the linear relationship between growth rates versus the tested temperatures provides the theoretical minimum growth rate (zero growth) (as $8.76^{\circ} \mathrm{C}$ in Table 2).

3. The maximum for this example can be determined as $30{ }^{\circ} \mathrm{C}$ (where the maximum growth rate occurred at 0.218 per day in Table (1), or at the point of inflection of the curve for growth periods in Figure (1), as well as the maximum rate of increase for the changes of reproductive capacity. $\left(r_{m}\right)$ (as 0.287 per day in Table 2).
Dynamics of plant phenomena and seasonal changes of pest counts:

The nutritional value of the host varies throughout the growing season. This relationship may represent different growth stages (i.e. vegetative growth, flowering, and fruits maturity stage), palatability (degree of ripeness of the host part) or the state of the plant's defense mechanism. This relationship can be linked to the physiological activity of the plant, from root biology to fruit ripening.

The dynamics of plant vegetation phenomena can be included mathematically as the age of the plant $(\mathrm{X})$ as a third (or higher) degree trend line from a polynomial model. Including this factor in the statistical procedures in polynomial partial regression models (including weather factors) resolves most of the variation as the dynamics of the plant vegetative phenomena $(\mathrm{X})$ are included as weeks that are raised to the second and third degrees of squared.

This equation becomes ( $\mathrm{Y}=\mathrm{a} \pm \mathrm{b}_{1} \mathrm{X} \pm \mathrm{b}_{2}$ $\left.X^{2} \pm b_{3} X^{3}\right)$ for the third degree of the polynomial (where $a=$ constant and $b_{1}, b_{2}$ and $b^{3}$ are the slopes of the first, second, and third parts of the response curve). $X^{2}$ and $X^{3}$ are the age of the plant in weeks raised to the second and third degrees of squared. This step can be executed using Excel application. 
After including the independent factors (maximum and minimum temperatures and relative humidity as linear models) the equation becomes $\left(\mathrm{Y}=\mathrm{a} \pm \mathrm{b}_{1} \mathrm{Tmax} \pm \mathrm{b}_{2} \mathrm{Tmin} \pm \mathrm{b}_{3} \mathrm{RH} \pm \mathrm{b}_{4} \mathrm{X} \pm \mathrm{b}_{5}\right.$ $\mathrm{X}^{2} \pm \mathrm{b}_{6} \mathrm{X}^{3}$ ).

Statistical analysis of this data including linear and non-linear factors can be performed using Proc Reg in the SAS statistical analysis program (Anonymous 2003).

This step reveals the value of the parameter of determination $\left(\mathrm{R}^{2}\right)$ for the proposed model or relationship and by multiplying by 100 we get the Explained Variance (EV \%).

This procedure is most clear in niley and winter crops, as the number of pest's increases during the gradual decrease in temperature or at the lowest temperature during the growing season. This is contrary to what is expected from laboratory studies. It reveals that the linear relationship between temperature and pest numbers increase from very low or negative values. Likewise, the combined effect of the activity of maximum and minimum temperatures and relative humidity, represented by $\mathrm{EV} \%$ is small or insignificant. In the mean time the relationship between the change in the population and the plant age of as third degree of the polynomial is more effective represented by the higher value of (EV \%) and therefore the explained variance is highly significant.

The following is an example of applying simple correlation and multiple regression for the effect of maximum and minimum temperatures and relative humidity data combined in conjunction with vegetative phenomena (i.e. plant age as third degree of polynomial) for $T$. urticae on three varieties of soybean during Jun. 2 to Sept.15, 2016 (after Anber et al. 2020).

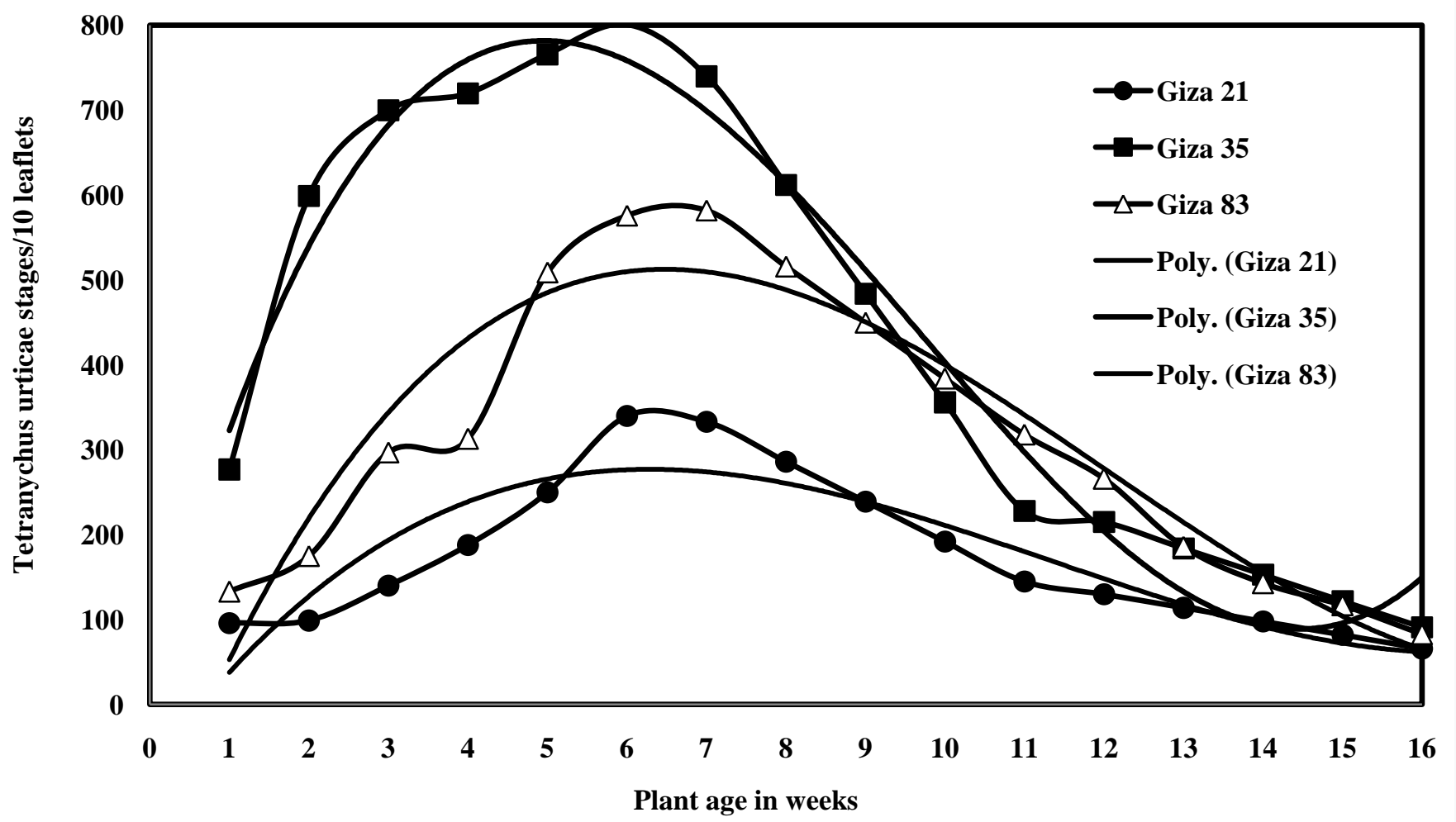

Figure 2. Weekly mean Tetranychus urticae counts on three varieties of soybean during Jun. 2 to Sept.15, 2016 (after Anber et al. 2020). 


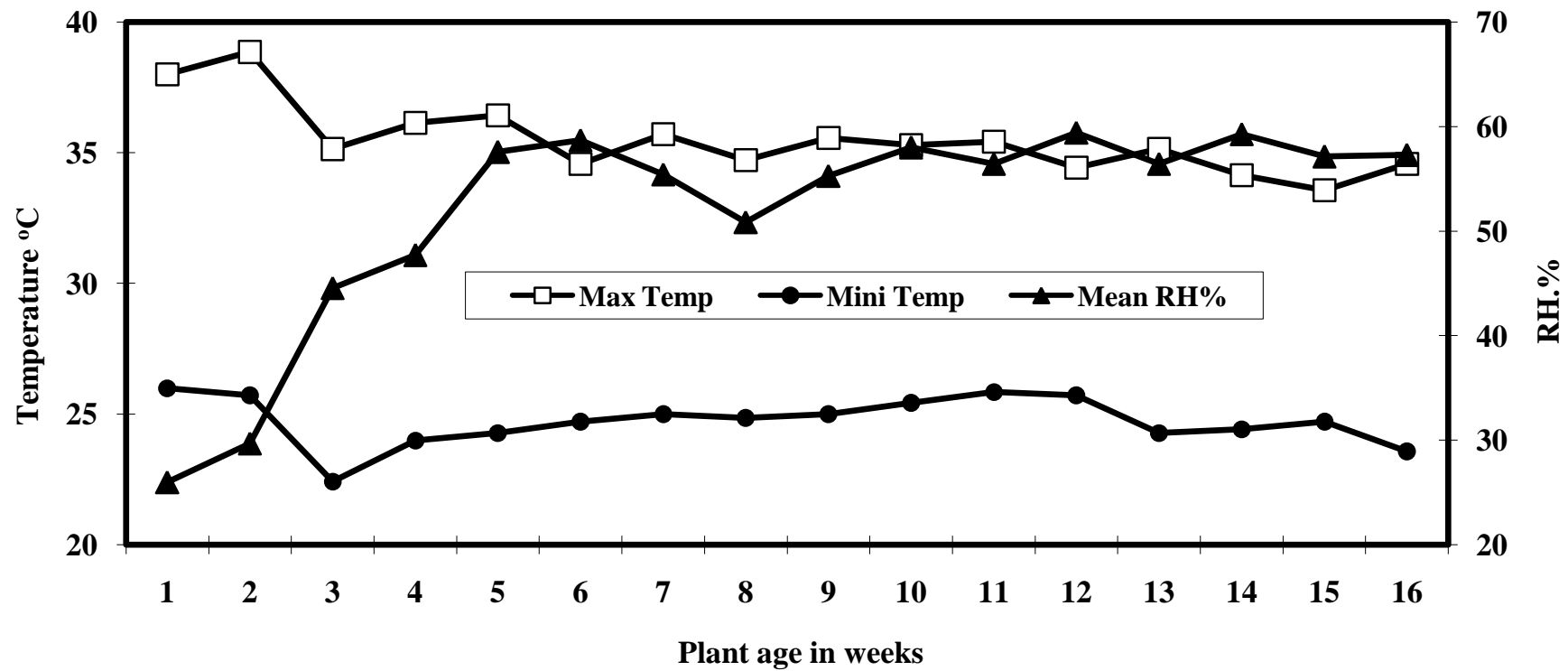

Figure 3. Weekly averages maximum and minimum temperatures and the percentage of relative humidity during the period from Jun. 2 to Sept. 15, 2016 (after Anber et al. 2020).

Table 4. Statistical output of the previous example (after Anber et al. 2020).

\begin{tabular}{|c|c|c|c|c|c|c|c|c|c|}
\hline \multirow{2}{*}{ Variety } & \multirow{2}{*}{ Factor } & \multirow{2}{*}{ Level } & \multicolumn{2}{|c|}{ Simple Correlation } & \multicolumn{5}{|c|}{ Multiple Regression } \\
\hline & & & $\mathrm{r}$ & $\mathrm{P}$ & $\mathrm{b}$ & $\mathrm{P}$ & $\mathrm{F}$ & $\mathrm{P}$ & $\mathrm{EV} \%$ \\
\hline \multirow{5}{*}{ G21 } & \multirow{3}{*}{ Weather } & Temp max & -0.059 & 0.8275 & 36.19 & 0.2896 & \multirow{3}{*}{0.830} & \multirow{3}{*}{0.5022} & \multirow{3}{*}{17.2} \\
\hline & & Temp min & 0.039 & 0.8846 & -0.98 & 0.9721 & & & \\
\hline & & RH & 0.279 & 0.2959 & 6.44 & 0.1488 & & & \\
\hline & Plant age & Age - Age $^{3}$ & - & - & 129.47 & 0.0003 & 20.05 & $<.0001$ & 83.37 \\
\hline & \multicolumn{2}{|c|}{ Combined } & - & - & - & - & 11.61 & 0.0009 & 88.56 \\
\hline \multirow{5}{*}{ G35 } & \multirow{3}{*}{ Weather } & Temp max & 0.333 & 0.8275 & 165.53 & 0.0821 & \multirow{3}{*}{1.760} & \multirow{3}{*}{0.2081} & \multirow{3}{*}{30.56} \\
\hline & & Temp min & -0.219 & 0.4159 & -122.24 & 0.1207 & & & \\
\hline & & RH & -0.174 & 0.5202 & 11.69 & 0.3148 & & & \\
\hline & Plant age & Age - Age $^{3}$ & - & - & 346.53 & $<.0001$ & 136.04 & $<.0001$ & 97.14 \\
\hline & \multicolumn{2}{|c|}{ Combined } & - & - & - & - & 53.28 & $<.0001$ & 97.26 \\
\hline \multirow{5}{*}{ G83 } & \multirow{3}{*}{ Weather } & Temp max & -0.046 & 0.8657 & 82.77 & 0.1918 & \multirow{3}{*}{1.180} & \multirow{3}{*}{0.3592} & \multirow{3}{*}{22.74} \\
\hline & & Temp min & 0.046 & 0.8656 & -3.79 & 0.941 & & & \\
\hline & & RH & 0.304 & 0.2531 & 14.16 & 0.0888 & & & \\
\hline & Plant age & Age - Age $^{3}$ & - & - & 236.41 & $<.0001$ & 41.94 & $<.0001$ & 91.29 \\
\hline & \multicolumn{2}{|c|}{ Combined } & - & - & - & - & 22.89 & $<.0001$ & 93.85 \\
\hline
\end{tabular}

It is noticeable that the relationship between weather factors and the populations were insignificant. Simple correlation values for daily maximum, minimal and \% RH ranged between -0.039 and 0.333 with $\mathrm{P}$ values between 0.253 and 0.8864 (insignificant correlation). This indicated no relation between weather factors over the growing seasons and $T$. urticae population dynamics. These results are confirmed by applying multiple regression analysis for the combined effect weather factors over the two seasons. No one factor showed significant effect within the weather factors (Tables 4). Obtained vales for plant age (presenting the change in the nutritional value of the host plant) were 83.37 to 97.26 for explained variance with $\mathrm{P}$ value of $<.0001$. The compiled 
effect of weather factors and plant age were not more significantly than plant age. This indicated that the change in the nutritional value of the host plant was more effective on mite population dynamics than weather factors.

In conclusion considering plant age as variable factor (with third degree of polynomial presenting the evolving nutritional value of the host plant) resolves the conflict between laboratory biological studies and field ecological ones.

\section{REFERENCES}

Abou-Setta MM, Sorrell RW, Childers CC. 1986. Life 48 A BASIC computer program to calculate life table parameters for an insect or mite species. Florida Entomologist, 69(4): 690-697.

Abou-Setta MM, Childers CC. 1991. Intrinsic rate of increase over different generation time intervals of insects and mite species with overlapping generations. Annals of the Entomological Society of America, 84:517521.

Anber HA, Younes AA, El-Shafei GM, Ammar MR. 2020. Population fluctuation of Tetranychus urticae Koch and the associated predatory mite Euseius scutalis
(A.-H.) on three Soybean cultivars at Gharbia Governorate. ACARINES, 14: 1320.

Anonymous 2003. SAS Statistics and graphics guide, release 9.1. SAS Institute, Cary, North Carolina 27513, USA.

Birch LC. 1948. The intrinsic rate of natural increase of an insect population. Journal Animal Ecology, 17: 15-26.

Caceres S, Childers CC. 1991. Biology and life tables of Galendromus helveolus (Acari: Phytoseiidae) on Florida citrus. Environmental Entomology, 20: 224-229.

Fouly AH, Abou-Setta MM, Childers CC. 1995. Effect of diet on the biology and life tables of Typhlodromalus peregrinus (Acari: Phytoseiidae). Environmental Entomology, 24: 870-874.

Kim T, Ahn J, Lee JH. 2009.Temperaturedependent developmental model of Neoseiulus californicus (McGregor) (Acari, Phytoseiidae). Journal of Applied Entomology, 133: 284-291.

Lotka AJ. 1925. Elements of physical biology. Baltimore, Tindall and Cox, pp460.

Winston PW, Bates DH. 1960. Saturated solutions for the control of humidity in biological research. Ecology, 41: 232-237. 